\title{
artigo
}

Branco, G.C.T.; Domingos, T.S.; Silveira, G.C.; Lopes, A.; Florentino, A.O.; D'Amico, G.C.S.;

Atuação da enfermagem nas práticas integrativas e complementares

\section{Atuação da enfermagem nas práticas integrativas e complementares}

\author{
Nursing performance in integrative and complementary practices \\ Rendimiento de enfermería en prácticas integrativas y complementaria
}

\begin{abstract}
RESUMO
Objetivos: Definir a atuação da enfermagem nas práticas integrativas e complementares. Metodologia: Realizou-se um estudo de revisão bibliográfica através das bases de dados SciELO e Biblioteca Virtual em Saúde. A pesquisa ocorreu no período de junho de 2018 a outubro de 2019, além disso, foram utilizadas outras fontes de pesquisa como sites do COFEN, COREN e Ministério da Saúde, cadernos e revistas de Saúde Pública e livros, devido ao conteúdo atual e/ou que auxiliaram enriquecendo as informações deste trabalho. Os descritores utilizados para a realização da revisão bibliografia foram: "Enfermagem", "Práticas Integrativas e Práticas Complementares". Resultados e Discussão: Menciona-se a necessidade de revisão dos planos terapêuticos de cuidado para a ampliação na inserção das práticas integrativas e complementares nos tratamentos de saúde, a necessidade de abordagens sobre a temática durante o período acadêmico dos universitários e a visão holística das práticas integrativas e complementares voltada para a saúde, individuo, sociedade e meio ambiente ao qual estão inseridos, seguindo os princípios e diretrizes SUS. Conclusão: A enfermagem está regulamentada para aplicar as técnicas/ procedimentos das práticas integrativas e complementares mediante a formação preconizada pela legislação COFEN, as quais consistem em métodos que enriquecem planos terapêuticos, a qualidade de vida dos pacientes e o trabalho da enfermagem.
\end{abstract}

DESCRITORES: Enfermagem; Práticas Integrativas; Práticas Complementares.

\section{ABSTRACT}

Objectives: To define the role of nursing in integrative and complementary practices. Methodology: A bibliographic review study was carried out through the SciELO and Virtual Health Library databases. The research took place from June 2018 to October 2019, in addition, other research sources such as COFEN websites were used, COREN and Ministry of Health, Public Health notebooks and magazines and books, due to the current content and / or that helped enrich the information in this work. The descriptors used to carry out the bibliography review were: "Nursing", "Integrative Practices and Complementary Practices". Results and Discussion: Mention is made of the need to review therapeutic care plans to expand the inclusion of integrative and complementary practices in health treatments, the need for approaches on the subject during the academic period of university students and the holistic view of practices integrative and complementary health, individual, society and environment to which they are inserted, following SUS principles and guidelines. Conclusion: Nursing is regulated to apply the techniques / procedures of integrative and complementary practices through the training recommended by COFEN legislation, which consist of methods that enrich therapeutic plans, patients' quality of life and nursing work.

DESCRIPTORS: Nursing; Integrative Practices; Complementary Practices.

\section{RESUMEN}

Objetivos: Definir el papel de la enfermería en las prácticas integradoras y complementarias. Metodología: Se realizó un estudio de revisión bibliográfica utilizando las bases de datos SciELO y la Biblioteca Virtual en Salud. La investigación se realizó entre junio de 2018 y octubre de 2019, además, se utilizaron otras fuentes de investigación como los sitios web de COFEN, COREN y el Ministerio de Salud, cuadernos de salud pública y revistas y libros, debido al contenido actual y / o que ayudó a enriquecer la información en este trabajo. Los descriptores utilizados para llevar a cabo la revisión bibliográfica fueron: "Enfermería", "Prácticas integradoras y prácticas complementarias". Resultados y Discusión: Se menciona la necesidad de revisar los planes de atención terapéutica para ampliar la inclusión de prácticas integradoras y complementarias en los tratamientos de salud, la necesidad de enfoques sobre el tema durante el período académico de los estudiantes universitarios y la visión holística de las prácticas. integrales y complementarios de salud, individuo, sociedad y entorno en el que se insertan, siguiendo los principios y directrices del SUS. Conclusión: La enfermería está regulada para aplicar las técnicas / procedimientos de prácticas integradoras y complementarias a través de la capacitación recomendada por la legislación COFEN, que consiste en métodos que enriquecen los planes terapéuticos, la calidad de vida de los pacientes y el trabajo de enfermería.

DESCRIPTORES: Enfermería; Prácticas Integradoras; Prácticas Complementarias.

RECEBIDO EM: 09/06/2020 APROVADO EM: 12/06/2020 


\section{Grace Cilene Torquarto Branco}

Enfermeira do Ambulatório de Pequenas Cirurgias do Hospital Amaral Carvalho de Jaú.

ORCID: 0000-0002-5153-2299

\section{Thiago da Silva Domingos}

Doutor em Enfermagem (se precisar). Professor Adjunto do Departamento de Enfermagem Clínica e Cirúrgica - Escola Paulista de Enfermagem - Universidade Federal de São Paulo (UNIFESP).

ORCID: 0000-0002-1421-7468

\section{Gercilene Cristiane Silveira}

Mestre em Ciências Área Pesquisa Clínica -Unesp Botucatu. Enfermeira Assistencial da Unidade Terapia Intensiva do Hospital Amaral Carvalho e Docente e Coordenadora do curso de Enfermagem das Faculdades Integradas de Jaú - FIJ.

ORCID: 0000-0002-1642-6917

\section{Adriane Lopes}

Enfermeira. Mestre em Administração, Educação e Novas Tecnologias. Docente das Faculdades Integradas de Jaú - FIJ. ORCID: 0000-0001-7221-7012

\section{Anelvira de Oliveira Florentino}

Mestre em Pesquisa Clínica pela Unesp Botucatu. Professor na IFSP Enfermagem; Enfermeira do Serviço e controle de infecção hospitalar no Hospital Unimed Sul Paulista.

ORCID: 0000-0001-8628-0565

\section{Giovana Cristina Serra D'amico}

Mestre em Pesquisa Clínica pela Unesp Botucatu. Professora: Faculdades Integradas de Jaú - FIJ e Professora: ETEC "Joaquim Ferreira do Amaral" - Jaú - CPS.

ORCID: 0000-0002-3397-0850

\section{INTRODUÇÃO}

$\mathbf{T}$ erapias Integrativas e Complementares (TIC) são métodos milenares de tratamento, prevenção e recuperação dos processos saúde/doença que agem através de elementos naturais e/ou vegetais, enxergam o indivíduo de forma holística - corpo, mente e espírito -, e, a partir dessa integração, objetivam o equilíbrio e a saúde completa do ser humano. São conceitos que visualizam o paciente em sua totalidade e não apenas como um conjunto de partes isoladas, sendo assim, se sobrepõem ao modo de cuidado técnico voltado apenas ao tratamento de doenças isoladas $^{(1-5)}$.

As TIC apresentam-se como práticas para integrar cuidados à saúde e/ou de forma complementar, atuando ao lado da medicina alopática/convencional, ou seja, deveriam caminhar em parceria para que o ser humano pudesse se beneficiar dos resultados positivos dessa integração ${ }^{(1,6)}$.

Para isso, o conhecimento a respeito das respostas positivas das TIC também deveria estar presente na educação e ser re- passado a todos os estudantes e profissionais de saúde, diminuindo e combatendo pré-conceitos estabelecidos devido à ausência do saber. Infelizmente, os benefícios oferecidos pelas TIC ainda são pouco conhecidos ou até mesmo ausentes de repasse nas instituições formadoras e, inclusive, nas instituições que prestam e oferecem serviços voltados à saúde ${ }^{(3,6-8)}$.

Florence Nightingale (protagonista e mãe da enfermagem moderna) em sua jornada, por meio de seus textos, já sugeria a utilização das práticas integrativas nos cuidados aos pacientes, que incluíam massagens "frias" ou "quentes", nutrição e a aplicação do óleo essencial de lavanda na região frontal dos soldados feridos com a intenção de acalmá-los. As TIC também se enquadram perfeitamente com a visão holística apresentada pela enfermeira Marta Rogers que, em sua teoria científica, descreve que o indivíduo é o resultado de suas integrações mútuas com o meio ambiente e suas variáveis ${ }^{(9)}$.

De acordo com a visão holística das Teorias de Enfermagem desenvolvidas por Myra E. Levine, Marta Rogers, Wanda
Aguiar Horta e Jean Watson, fazendo-se junção à Organização Mundial de Saúde (OMS), de maneira integrada e globalizada, a saúde para o homem se define como a manutenção e bem-estar de todos os ângulos de vivência humana, como: alimentação, sociabilidade com a família, amigos, natureza e meio ambiente onde este está inserido, concretização de projetos, bem- estar físico, mental e a qualidade de vida, pois o ser humano é holístico ${ }^{(9-11)}$.

Conduzindo-se conforme a esse conceito generalizado e ajustado, é possível reforçar e valorizar ainda mais as convicções das terapias complementares sobre a eficiência oferecida no cuidado pelas práticas não convencionais, pois estas podem ser consideradas: integrativas (interagem entre os saberes biomédicos e tradicionais, cuidando do indivíduo em sua totalidade), complementares (participam dos tratamentos ao ser humano ao lado da medicina convencional), alternativas (quando trabalham sozinhas descartando outros meios de cuidado), tradicionais (pois são milenares, antecedendo a medicina cartesiana) e não convencionais - caminham de 
acordo aos seus preceitos, muitas vezes se contrapondo a métodos da biomedicina convencional ${ }^{(11,13)}$.

Conseguinte, pode-se considerar que as TIC são um conjunto de meios facilitadores para integração paciente-enfermagem, complementos naturais que se integram ao tratamento convencional, que o profissional enfermeiro poderá exercer mais do que somente os cuidados convencionais instituídos por formadores e organizações tradicionais, voltados somente aos problemas físicos que o paciente apresenta, aumentando sua autonomia profissional na prestação de cuidados à saúde e bem-estar geral do ser-humano ${ }^{(3,6)}$

O Conselho Federal de Enfermagem (COFEN) reconhece a profissão de enfermagem em sua fundamentação holística de cuidado por meio do Parecer Informativo n. ${ }^{\circ} 004 / 95$, pelo qual se justifica a utilização das TIC $^{(2,14)}$.

Através do Anexo da Resolução n. ${ }^{\circ}$ $0581 / 2018$, que fala a respeito das especialidades do enfermeiro por área de abrangência, constitui as TIC como especialidade e/ou qualificação do profissional Enfermeiro, realidade, na maioria das vezes, deficiente de repasse ou, em alguns casos, ausente do conhecimento de acadêmicos de enfermagem e inclusive de profissionais já graduados ${ }^{(15)}$.

Com base na Política Nacional de Práticas Integrativas e Complementares (PNPIC), aprovada pela portaria GM/ MS n. ${ }^{\circ}$ 971, em de 03 de maio de 2006, foram implementadas no Sistema Único de Saúde (SUS) diretrizes e responsabilidades institucionais, fornecendo aos cidadãos brasileiros o direito de receberem a oferta de serviços ao atendimento de algumas TIC, como: homeopatia, medicina tradicional chinesa/ acupuntura, plantas medicinais e fitoterapia, além de constituir observatórios das experiências de medicina antroposófica e termalismo social/ crenoterapia $^{(1,6,9,16,17)}$.

Com o decorrer do tempo ocorreram renovações nas diretrizes SUS e, em março de 2017, houve ampliação em outras novas práticas determinadas pela Portaria GM/MS n. ${ }^{\circ} 847 / 2017$, sendo estas: arteterapia, ayurveda, biodança, dança circular, meditação, musicoterapia, naturopatia, osteopatia, quiropraxia, reflexoterapia, reiki, shantala, terapia comunitária integrativa e $\operatorname{yoga}^{(16)}$.

E ainda, recentemente, em 2018, foi agregado à PNPIC a Portaria de n. ${ }^{\circ} 702$, em 21 de março de 2018, na qual consta a aprovação da inclusão das seguintes práticas no atendimento SUS: aromaterapia, apiterapia, bioenergética, constelação familiar, cromoterapia, geoterapia, hipnoterapia, imposição de mãos, medicina antroposófica/antroposofia aplicada a saúde, ozonioterapia, terapia de florais e termalismo social/crenoterapia aplicados a saúde ${ }^{(16-18)}$.

Desde 2006, com o desenvolvimento da PNPIC o Ministério da Saúde juntamente com a OMS vem valorizando a utilização dos termos: "Práticas Integrativas", pois eles agregam e interagem entre os diferentes conceitos de cuidados, descartando-se as definições já existentes: "Medicinas Não Convencionais", "Terapias Alternativas", "Práticas Populares" e "Medicinas Naturais", pois traziam consigo o entendimento que o paciente pode ter como alternativa somente alguns tipos de tratamento, menosprezando um e valorizando outro, assim sendo, reforça-se que as Práticas Integrativas e Complementares (PIC) agregam benefícios aos cuidados do paciente juntamente a medicina convencional ${ }^{(9)}$.

Com todas essas ampliações, há necessidade de se discutir a respeito das PIC que são de competência, execução e aplicação, para o cuidado a saúde, por parte do profissional graduado em enfermagem, segundo a legislação $\operatorname{COFEN}^{(6,7)}$.

Mantendo a esperança de que essa sabedoria poderá abranger e beneficiar um número cada vez maior de pacientes com a utilização e os resultados benéficos oferecidos pelas TIC, ampliando as abordagens de cuidado e as possibilidades terapêuticas para os usuários, garantindo uma maior integralidade e resolutividade da atenção à saúde ${ }^{(4,6)}$.

Então, a partir da construção dessas ideias, é possível salientar o quão impor- tante é que o profissional de enfermagem detenha esse tipo de conhecimento específico e que, durante a graduação, os acadêmicos sejam preparados e saibam se manifestar com clareza e corretamente quanto a essas questões. Despertar o interesse do aluno a respeito das terapias alternativas se torna imprescindível, já que são áreas de atuação reconhecidas e identificadas pela legislação de enfermagem e podem favorecer o trabalho dos enfermeiros e a saúde dos pacientes ${ }^{(1,4,7,8)}$.

Desta forma, objetivou-se discutir a atuação da enfermagem nas práticas integrativas e complementares.

\section{METODOLOGIA}

Para o desenvolvimento dos objetivos propostos por este trabalho, foi produzida a questão norteadora que direcionou sua execução: "Qual a atuação da enfermagem nas Práticas Integrativas e Complementares que o enfermeiro pode atuar?". Houve uma pesquisa por textos científicos através da Biblioteca Virtual de Saúde (BVS) e Scientific Electronic Library Online (SciELO) sendo realizada uma revisão bibliográfica, utilizando as palavras-chave fornecidas pelos descritores da BVS, aplicando-se o operador "and" e fazendo o uso do filtro na opção Língua Portuguesa, o objetivo da busca nas bases de dados constou como: "enfermagem and práticas integrativas and práticas complementares".

A seleção dessas bases de dados ocorreu devido ao fácil acesso, autenticidade e análises críticas e científicas delas. E, como resultado, foram obtidos 268 materiais relacionados ao tema desta pesquisa.

Após o levantamento de todo material disponibilizado pelas bases de dados, ocorreu a organização das informações contidas no título e resumo de cada uma das obras literárias e somente o que correspondia as questões determinantes a execução desse trabalho foi selecionada. $\mathrm{O}$ processo de exclusão desconsiderou obras duplicadas e que apenas citassem as palavras-chave, porém seu conteúdo era irrelevante, não atingindo os objetivos propostos na pesquisa. 
$\mathrm{Na}$ sequência, foi realizada a leitura e revisão na íntegra de 36 obras e selecionados 19 estudos.

Sendo também que houve a necessidade de buscar informações adicionais em sites, cadernos e revistas de Saúde Pública do Ministério da Saúde, sites do COREN e COFEN por conter informações atualizadas a respeito da legislação que organiza as Práticas Integrativas e Complementares no exercício da enfermagem.

A análise destes estudos ocorreu no período de junho de 2018 a outubro de 2019 e seus resultados foram apresentados, neste trabalho, seguindo a ordem cronológica conforme a ordem natural de fatos e acontecimentos.

\section{RESULTADOS E DISCUSSÃO}

A forma de cuidar das práticas completares leva em consideração a integração do indivíduo consigo mesmo, com seu meio ambiente, com os seus lados psicológicos e sua espiritualidade (essência do que o ser é e crê), as respostas fornecidas pelo organismo estão de acordo com essa totalidade e as influências externas que são capazes de causar conflitos. Suas filosofias estão fundamentadas no entendimento de que os indivíduos são capazes de interatuar com a natureza e socialmente, são práticas de cuidado centradas na saúde e não na doença ${ }^{(5,11)}$.

No entanto, a medicina convencional está baseada no pensamento cartesiano, influenciada por Descartes e nos conceitos de anatomia/fisiologia, os quais dividem o corpo humano em partes cada vez menores, como por exemplo: sistema reprodutor, útero, ovário, trompas, glândulas, células, e entre outras pequenas partes, para a realização de diagnósticos e tratamentos onde o corpo humano pode ser considerado uma máquina, e seus órgãos peças, que podem ou não apresentar problemas/defeitos, sendo estas filosofias consagradas, pois estão de acordo com a biologia, contendo comprovações científicas que garantem sua eficiência/eficácia e facilitam a aplicação dos tratamentos. Esse modelo da medicina cartesiana tem beneficiado de forma incontável a inúmeros doentes ${ }^{(1,11,13,19)}$.

As terapias integrativas são capazes de tratar e complementar a assistência a pacientes em diversas situações, como: hipertensão arterial sistêmica, redução do nível de colesterol na corrente sanguínea, cuidar de problemas cardíacos como a angina, arritmia, diminuir as dores das contrações do trabalho de parto de maneira mais natural, diminuir incômodos produzidos durante a gestação, redução das dores lombares ou dores crônicas espalhadas pelo corpo, cicatrização de feridas, redução de ansiedade, melhoria da qualidade de vida de pessoas idosas, contribui com a recuperação das atividades motoras e cognitivas de pacientes pós cirúrgicos, previne doenças, conscientiza o sujeito sobre o autocuidado, causam menos efeitos colaterais e reações adversas, fortalecem o sistema imunológico, reduzem infecções, problemas estomacais e respiratórios, desenvolve disposição física, reduz a fadiga e sintomas de várias patologias. Em pacientes psiquiátricos, proporciona: tranquilidade, melhoria do vínculo com o profissional de saúde, equilibro emocional, clareza mental, redução no consumo de psicotrópicos entre outros ${ }^{(19,20)}$.

Em sujeitos que se apresentam hospitalizados, pré ou pós cirúrgicos, ou/e recebendo cuidados quimioterápicos, ou/e em estado de atribulação psicológica, com dores e sofrimentos físicos, situações onde não há recuperação, são atribuídos a estes indivíduos apenas cuidados/tratamentos convencionais para o alívio e conforto de seu estado clínico geral, as terapias são capazes de contribuir, reduzindo dores, tranquilizando estados psicológicos alterados, melhorando a qualidade do sono, diminuindo irritabilidade, ansiedade, trazendo relaxamento e entre outros benefícios que podem complementar a medicina atual ${ }^{(19)}$.

Para todos os pacientes, os métodos das práticas integrativas de cuidado à saúde proporcionam: acolhimento, atendimentos mais humanizados e menos invasivos, meio-ambiente de cuidado mais confiável e confortável, contribuindo e respeitando as individualidades pessoais de cada um.
Todos esses benefícios e muitos outros podem ser alcançados com a utilização das Terapias Complementares, porém a escolha da prática adequada às necessidades do paciente deve ser guiada por um profissional competente, pois cada uma possui indicações que se encaixam com maior eficácia/eficiência nas moléstias já citadas e até mesmo em outras ${ }^{(5,13)}$.

Atualmente na área da saúde, estão ocorrendo transformações onde se exige e é necessária a integração entre a medicina convencional e as práticas complementares. Estão fazendo parte dos conceitos da saúde temas, como: clínica ampliada, humanização do atendimento, entrosamento das técnicas de saúde, constantes mudanças nos padrões técnicos assistenciais, formulação do vínculo terapêutico através da integração entre o profissional de saúde/ paciente e a escuta acolhedora ${ }^{(5,11,13)}$.

Enquanto as teorias que embasam os conhecimentos da medicina alopática dividem e diminuem o corpo do indivíduo em apenas "peças" para o tratamento das doenças, reduzindo a integralidade do paciente consigo mesmo e com todo o meio externo, nas terapias complementares a integração é a raiz fundante de seu conhecimento, permitindo dimensões ética e epistemológica, sendo de fácil observação notar que um tratamento é focado nas doenças e o outro visa o ser humano e as causas externas que interagem com ele provocando as doenças. Comandando a anos os serviços voltados à saúde, muitos médicos rejeitam os tratamentos oferecidos pelas práticas complementares, podendo isso estar relacionado à falta de conhecimento, pois são temas deficientes de abordagem nas universidades, onde o foco é inteiramente voltado para o ensinamento da medicina alopática, medicalização e as técnicas/procedimentos laborais de saúde, situações que evidenciam a necessidade de transformações urgentes nas instituições educacionais, graduando profissionais menos incrédulos e preconceituosos, possuindo maior capacidade de atuar na área da saúde ${ }^{(8,21)}$.

Portanto, se faz necessário questionar até onde se permite que o modelo de me- 
dicina cartesiana atual interfira na aplicação dos tratamentos oferecidos pelas terapias integrativas, tornando as práticas não convencionais fragmentadas e isoladas. Fazendo-se apropriado destacar que a integração entre os modos convencionais e não convencionais de cuidado à saúde garantem tratamentos éticos e com qualidade, portanto, o profissional de saúde que decide optar em realizar seu trabalho de acordo com as práticas integrativas e complementares, deve também manter/ utilizar o respeito aos conhecimentos que foram adquiridos com o estudo da biologia/anatomia/fisiologia/patologia, pois estes fundamentam o seu saber ${ }^{(13)}$.

A enfermagem, principalmente no contexto do ambiente hospitalar, é muito influenciada pela medicina convencional, todas suas atividades, procedimentos, realização de cuidados, abordagens e intervençôes são realizados de acordo com os conceitos estabelecidos pela medicina atual, levantado dúvidas e questionamentos a respeito de: "Quais terapias integrativas devem ser aplicadas no ambiente hospitalar e fora (clinicas, consultórios ou outras instituições de saúde)?" e "quais delas podem ser exercidas pela enfermagem?", pois atualmente, é o modelo biomédico de cuidado que sustenta a composição universitário/profissional competente ${ }^{(6,13)}$.

Estimular argumentos que conduzam a inserção das terapias complementares no ambiente hospitalar e sua aplicabilidade pela enfermagem, surte como forma de harmonizar e corrigir os constantes detrimentos que se formam há séculos entre essas diferentes técnicas de tratamento à saúde, mesmo porque a natureza das práticas integrativas mantem-se aberta aos colóquios de diferentes conceitos, pontos de vista, filosofias, técnicas, práticas e atuações. O que se mostra preocupante é quando conceitos/ciências/filosofias/tratamentos/terapias se reduzem, ao ponto de prejudicar a totalidade do indivíduo ${ }^{(6,13,22)}$.

Associação Brasileira de Terapias Naturais em Enfermagem (ABRATEM) aponta a ausência do ensino sobre as disciplinas de Terapias Integrativas e Complementares nos currículos das instituições que realizam a formação na graduação de enfermagem, o que pode motivar em contratempos, pois o enfermeiro é um dos profissionais de saúde mais próximo ao paciente, também responsável por transmitir orientações seguras, proporcionando conscientização a respeito da utilização das práticas integrativas, mecanismos de ação, bem como os efeitos colaterais adversos, interações medicamentosas, benefícios e riscos quando estas interagem com a medicina convencional ou sozinhas, desenvolvendo uma abordagem integral baseada em conclusões normatizadas e científicas, integrando e valorizando o conhecimento cultural da populaçãoo ${ }^{(8,19,22)}$.

A ausência do ensino de terapias complementares pode ser confirmada em esfera nacional, pois durante a formação acadêmica ou em pós-graduação de muitos profissionais de saúde, a maior parte das universidades em suas disciplinas aborda superficialmente ou não aborda terapias complementares, os temas relacionados aos cuidados de saúde são focados na clínica patológica/farmacológica/tecnicista, não conduzindo a uma abordagem abrangente, evidenciando a carência de estudos e pesquisas nesse assunto ${ }^{(6,8)}$.

Conforme apontamentos das pesquisas literárias, mesmo a enfermagem já graduada possuindo teorias que embasam seu exercício profissional nas terapias complementares, ainda assim, alguns sentem-se desqualificados para orientar ou executar técnicas simples, devido à falta de comunicação entre profissional/usuário, ausência de aprofundamento teórico, desvalorização dos tratamentos realizados pelas PIC por outros profissionais e a ausência de protocolos que disponham sobre as práticas complementares. Se a enfermagem estivesse preparada, poderia complementar e integrar ao seu exercício clínico as práticas não convencionais, empregando-as nas consultas de enfermagem, durante as visitas terapêuticas, exames físicos, diagnósticos de enfermagem, acompanhamento da evolução do paciente, avaliação das terapêuticas utilizadas e entre outras atividades, assim, estaria enriquecendo diagnósticos clínicos, transformando o cuidado à saúde cada vez mais integral e holístico pela combinação entre o saber não convencional e o alopático, convertendo as terapias integrativas em tecnologias inovadoras que abrem espaço e novas opções abrangentes para a atuação profissional ${ }^{(8,12,13,22,23)}$.

Existe também o obstáculo de que, mesmo as Terapias Complementares sendo técnicas legalizadas pelo Ministério da Saúde, infelizmente até este momento seu acesso aos populares é limitado e não abrange completamente o território nacional, o que se contrapõe ao baixo custo que elas possuem para implementação, fator importante e viável para o sistema público de saúde já que são técnicas que se abastecem de benefícios, eficácia e eficiência comprovadas cientificamente, de igual valor aos oferecidos pela medicina convencional, contribuindo com a humanização, trazendo luz a conceitos como autonomia e autocuidado por parte do paciente em relação à própria saúde e à sociedade $\mathrm{e}^{(5,11)}$.

Estudos revelam que as terapias alternativas têm sido utilizadas cada vez mais pela população na tentativa de alcançar melhorares condições de saúde, elevando sua procura em $46 \%$, passando de $216 \mathrm{mil}$ atividades desenvolvidas para $315 \mathrm{mil}$, entre os anos de 2017 e 2018. Infelizmente, em decorrência das dificuldades para se encontrar clínicas e profissionais especializados nas áreas competentes, acabam se sujeitando aos tratamentos com terapeutas que nem sempre possuem formação na área da saúde ${ }^{(6,10,8,22)}$.

No glossário temático de terapias alternativas e complementares, pode-se encontrar diversas medidas públicas instituídas teoricamente para introdução e implementação das terapias alternativas, portanto, a adesão de medidas práticas e técnicas por parte do Ministério da Saúde para tornarem a implementação e acesso das medicinas integrativas seguros e qualificados, visando a adequada distribuição dos profissionais capacitados e condições para o exercício legal das terapias em todo o território nacional, as quais devem ser alicerçadas imediatamente, pois o respal- 
do teórico já está em exercício desde o ano de 2006 com PNPIC $(5,13,16,18,19)$.

Análises científicas indicam que em países, como Estados Unidos, Israel, Alemanha, Espanha, Canada, México, Reino Unido, Taiwan, Coreia e Japão, as PIC já estão inseridas ou são mencionas com ênfase nas grades disciplinares há algumas décadas, seguindo uma larga escala da expansão mundial, conforme está preconizado pelos cuidados de saúde recomendados pela OMS. No Brasil, esse conhecimento é mais privativo em instituições de ensino não público e em apenas uma pequena parcela dessas instituiçóes privadas este ensino é lecionado, o que torna ainda mais dificultoso a integração e implementação das práticas integrativas no sistema de saúde brasileiro, principalmente por parte dos profissionais, pois por não serem conscientes a respeito desses saberes, desvalorizam e desintegram as terapias complementares nos cuidados aos doentes ${ }^{(8,21)}$.

Para que a PNPIC se torne efetivamente prática, podendo o usuário de saúde de todo território nacional ter acesso aos seus benefícios, é necessário vencer obstáculos: como: ausência de conhecimento dos administradores de saúde para realizar sua implementação técnica na atenção primária de saúde de seus respectivos municípios, programas de parceria governamental com as universidades públicas/privadas e instituições que treinam profissionais de saúde garantindo o acesso à educação e ao conhecimento das terapias complementares e elucidando a aproximação entre os terapeutas tradicionais e os profissionais de saúde, disposição da relação de plantas medicinais e fitoterápicos apontados pelos sistemas de saúde, com intenção de atingir o acesso à saúde para todos de maneira integral com qualidade e segurança ${ }^{(17)}$.

Se todos esses obstáculos forem vencidos e houver a incorporação dessas medidas nos sistemas de educação/saúde, também irão contribuir para reduzir conceitos populares inviáveis, como por exemplo: "o uso de planta medicinal não faz mal, por ser natural", que quando somado a outra ideia popular: "médicos não entendem de plantas medicinais", levam aos pacientes a não serem ín- tegros nas abordagens clinicas dificultando o sucesso dos tratamentos pela ausência de uma prescrição adequada aumentando os riscos de interação medicamentosa ${ }^{(11)}$.

\section{CONCLUSÃO}

Em sua trajetória no SUS, as TIC vêm desenvolvendo a própria validação, pois por meio de seus talentos, aptidôes e processos não alopáticos, nos conceitos saúde/doença/cura, progridem nas táticas de reconhecer as doenças e aplicar terapêuticas bem-sucedidas que amparam a plenitude integral do cuidado e do ser humano.

Suas atividades agradam os pacientes e, entre suas inúmeras vantagens, pode-se citar as que mais se destacam: bem-estar físico, mental, espiritual e social, felicidade, saúde, cura de enfermidades, prevenção de doenças, naturalidade, expansão, sociabilidade, comunicabilidade e lazer, alívio da dor, tranquilidade, redução de sinais e sintomas das enfermidades que afetam o organismo, relaxamento, bem-estar físico e mental, diminuição da ansiedade e irritabilidade, instiga a conexão e a confiabilidade ente usuários dos serviços de saúde e seus profissionais, diminui a utilização de drogas farmacológicas, reduz de efeitos colaterais, desenvolve a resistência imunológica, melhora da qualidade de vida, torna o indivíduo mais sociável nos relacionamentos com outros e com a natureza, e também mais participativo de atividades.

É necessário a atuação e o heroísmo da enfermagem no preparo e convencimento dos profissionais e usuários da saúde que participam de instituições, estabelecimentos e clínicas médicas a respeito das Práticas Integrativas e Complementares. E que durante a execução qualificada das terapias não convencionais, a enfermagem esteja apta para contribuir, oferecendo tratamentos éticos e seguros, que valorizem as práticas integrativas e reduzam os custos financeiros da saúde. Ficando esclarecido que a mais atual Resolução do COFEN do ano de 2018, a respeito da atuação da enfermagem nas práticas integrativas, estabelece as apenas as seguintes terapias: Fitoterapia, Homeopatia, Orto- molecular, Terapia Floral, Reflexoterapia Podal, Reiki, Yoga, Toque Terapêutico, Musicoterapia, Cromoterapia, Hipnose e Acupuntura, como qualificação normatizada somente para o exercício profissional do enfermeiro com título de graduação aprovado pelo MEC.

Sendo de suma importância destacar que as disciplinas de terapias complementares sejam implementadas nas grades curriculares das instituições que formam acadêmicos de enfermagem e outros universitários da área da saúde, e que este tema também seja debatido e mencionado pela educação continuada das instituições, onde profissionais já graduados da saúde exercem suas atividades laborais, pois o COFEN já concede ao enfermeiro o amparo legal para atuação nas práticas integrativas e complementares. Portanto, a contribuição entre os profissionais de saúde é almejada, pois o conhecimento da população a respeito das práticas integrativas já não está mais no anonimato e vem aumentando a cada dia, levando maior procura por acessibilidade, portanto, os profissionais de saúde precisam estar preparados.

Assim sendo, é essencial que ocorram análises e inspeções com intervalos regulares por profissionais enfermeiros que estejam de acordo com a legislação COFEN e atuem em suas referidas áreas das práticas integrativas para melhorias no atendimento das assistências prestadas. Isto posto, é possível reconhecer que o trabalho da enfermagem recebe empoderamento, maior autonomia e independência através das PIC. Considerando também que a implementação das terapias complementares permite e facilita a participação popular pela busca de seus interesses, transformando-os em intermediários na negociação da saúde como cidadãos inseridos na sociedade.

Dessa maneira, espera-se que este estudo abra portas para novas investigações e reflexões, as quais possibilitem a inserção das terapias integrativas nos contextos hospitalares, atenção primária e básica de saúde no SUS e universidades, abrangendo um número cada vez maior de pacientes e profissionais na área da saúde. 


\section{REFERÊNCIAS}

1. Alvim NAT, et al. Práticas Integrativas e Complementares no Cuidado: Aplicabilidade e Implicações para a Enfermagem. $17^{\circ}$ SENPE Seminário Nacional de Pesquisa em Enfermagem [Internet], Natal/RN, jun. 2013 [acesso em 19 jun 2018]. Disponivel em: http:/www.abeneventos.com.br/anais_senpe/17senpe/pdf/0070pr.pdf.

2. Trovo MM, et al. Terapias alternativas/complementares no ensino público e privado: análise do conhecimento dos acadêmicos de enfermagem. Rev. Latino-amer. Enferm. [Internet]. 2003 [acesso em 13 jun 2018];11(4):483-489. Disponivel em: http:/www.scielo.br/pdf/rlae/ v11n4/v11n4a11.

3. Silva $\mathrm{CM}$, et al. Estratégias de ensino das terapias alternativas e complementares na graduação em Enfermagem: revisão integrativa. Rev. Eletr. Enferm. [Internet]. 2013 dez [acesso em 19 jun 2018];15(4):1061-1067. Disponivel em: https:/www.revistas.ufg.br/ fen/article/view/20568.

4. Garvin ROS, et al. Terapias alternativas e complementares: uma visão do conhecimento dos acadêmicos de enfermagem. Ciênc. Cuidado e Saúde [Internet]. 2010 [acesso em 13 jun 2018];9(4):760-765. Disponivel em: http:/periodicos.uem.br/ojs/index.php/CiencCuidSaude/ article/view/13827.

5. Barreiros RN. et al. Craniopuntura Japonesa como Instrumento para o Tratamento da Dor não Específica em Profissionais de Saúde. Rev. On Line de Pesq. Cuid. Fundam. [Internet]. 2019 [acesso em 06 jul 2019];11(3):594-598. Disponivel em: http://www.seer.unirio.br/index. php/cuidadofundamental/article/view/6594/pdf_1.

6. Pennafort VPSP, et al. Práticas integrativas e o empoderamento da enfermagem. Rev. Min. Enferm. [Internet]. 2012 [acesso em 19 jun 2018];16(2):289-295. Disponivel em: http://reme.org.br/artigo/detalhes/531\#.

7. Barros NF, Toney P. $\mathrm{O}$ ensino das terapias alternativas e complementares em escolas de enfermagem. Rev. Gaúcha Enferm [Internet]. 2007 [acesso em 18 jun 2018];28(2):207-214. Disponivel em: http:/ www.seer.ufrgs.br/index.php/RevistaGauchadeEnfermagem/article/ view/3165/1736.

8. Nascimento MC, et al. Formação em práticas integrativas e complementares em saúde; desafios para universidades públicas. Trab. Educ. Saúde [Internet]. 2018 [acesso em 10 jun 2019];16(2):751-772. Disponivel em: http:/www.scielo.br/scielo.php?script=sci_arttext\&pid=S1981-77462018000200751.

9. Gnatta JR, et al. Aromaterapia e enfermagem: concepção histórico-teórica. Rev. Esc. Enferm. USP [Internet]. 2016 [acesso em 19 jun 2018];50(1):127-133.Disponivel em: <https:/www.revistas.usp.br/ reeusp/article/view/112702/110628.

10. Nunez HMF, Ciosak SI. Terapias alternativas/complementares: o saber e o fazer das enfermeiras do distrito administrativo 71 - Santo Amaro - São Paulo. Rev. Esc. Enferm. USP [Internet]. 2003 [acesso em 07 jul 2019];37(3):11-18. Disponivel em: www.scielo. br/scielo.php?script=sci_arttext\&nrm=iso\&lng=pt\&tIng=pt\&pi$\mathrm{d}=$ S0080-62342003000300002.

11. Matos PC, et al. Práticas integrativas e complementares na atenção primária de saúde. Cogitare Enferm [Internet]. 2018 [acesso em 09 jul 2019];23(2):e54781. Disponivel em: http:/www.revenf.bvs.br/scielo.
php?script=sci_arttext\&pid=S1414-85362018000200321.

12. Salles LF, Silva MJP. Enfermagem e as Práticas Complementares em Saúde. São Caetano do Sul: Yendis Editora; 2011. P. 227.

13. Melo SCC, et al. Práticas complementares de saúde e os desafios de sua aplicabilidade no hospital: visão de enfermeiros. Rev. Bras. Enferm. [Internet]. 2013 [acesso em 02 jul 2019];66(6):840-846. Disponível em: $\quad$ www.scielo.br/scielo.php?script=sci_arttext\&nrm=iso\&lng=pt\&tlng=pt\&pid=S0034-71672013000600005.

14. Conselho Federal de Enfermagem (BR). Resolução Cofen n. ${ }^{\circ}$ 197/1997 [Internet]. Brasilia (DF): COFEN, 1997[acesso em 19 out 2019]. Disponivel em: http:/www.cofen.gov.br/resoluo-cofen-1971997_4253.html.

15. Conselho Federal de Enfermagem (BR). Resolução Cofen n. ${ }^{\circ}$ 581/2018 [Internet]. Brasilia (DF): COFEN, 2018 [acesso em 29 out 2018]. Disponivel em: http:/www.cofen.gov.br/resolucao-cofen-no-581-2018_64383.html.

16. Ministério da Saúde (BR). Glossário temático: práticas integrativas e complementares em Saúde [Internet]. Brasilia (DF): MS, 2018 [acesso em 29 out 2018]. Disponivel em: http:/portalarquivos2.saude.gov.br/ images/pdf/2018/marco/12/glossario-tematico.pdf.

17. Assis WC, et al. Novas formas de cuidado através das práticas integrativas no sistema único de saúde. Rev. Bras. Prom. Saúde [Internet]. 2018 [acesso em 12 jul 2019];31(2):1-6. Disponivel em: https:/periodicos.unifor.br/RBPS/article/view/7575.

18. Ministério da Saúde (BR). Portaria n. ${ }^{\circ}$ 702, de 21 de março de 2018. Poder e Saúde [Internet]. Brasilia (DF): MS, 2018 [acesso em 03 nov 2018]. Disponivel em: https:/www.poderesaude.com.br/novosite/ images/22.03.2018_l.pdf.

19. Mendes DS, et al. Benefícios das práticas integrativas e complementares no cuidado de enfermagem. Journal Health NPEPS [Internet]. 2019 [acesso em 03 jul 2019];491):302-318. Disponível em: http:/ docs.bvsalud.org/biblioref/2019/06/999705/3452-12861-7-pb.pdf.

20. Carvalho JLS, Nóbrega MPSS. Práticas integrativas e complementares como recurso de saúde mental na Atenção Básica. Rev. Gaúcha Enferm [Internet]. 2017 [acesso em 03 nov 2018];38(4):1-9. Disponível em: http:/www.scielo.br/pdf/rgenf/v38n4/1983-1447-rgenf-38-04-e2017-0014.pdf.

21. Lopes ACP, et al. As contribuições da disciplina "terapias complementares com ênfase em plantas medicinais" na prática profissional dos enfermeiros. Rev. On Line Pesq. Cuid. Fundam. [Internet]. 2018 [acesso em 13 jul 2019];10(3):619-625. Disponível em: www.seer.unirio.br/index.php/cuidadofundamental/article/viewFile/6127/pdf_1.

22. Feitosa MHA, et al. Inserção do Conteúdo Fitoterapia em Cursos da Área de Saúde. Rev. Bras. Educ. médica [Internet]. 2016 [acesso em 23 jul 2019];40(1):197-201. Disponivel em: http:/www.scielo.br/scielo. php?script=sci_arttext\&pid=S0100-55022016000200197.

23. Medeiros SP, et al. Percepção de Estudantes de Graduação em Enfermagem Acerca do Recebimento do Toque Terapêutico. Rev. On Line Pesq. Cuid. Fundam. [Internet]. 2019 [acesso em 05 jul 2019];11(Esp):464-469. Disponivel em: www.seer.unirio.br/index. php/cuidadofundamental/article/view/6388/pdf 